\title{
METHYL BROMIDE INTOXICATION
}

\author{
BY \\ H. WYERS
}

From the Health Department, May and Baker Limited, Dagenham

The first known cases of methyl bromide poisoning, occurring in 1893, were two in number and were recorded by Jacquet in 1901. By 1934 Carozzi had been able to collect 27 cases, 5 of which were doubtful. Since then a number of established cases have occurred and this paper contains a review of the present knowledge of methyl bromide intoxication and records nine further cases.

\section{Chemistry}

Methyl bromide $\left(\mathrm{CH}_{3} \mathrm{Br}\right)$, molecular weight 94 , boils at $4.5^{\circ} \mathrm{C}$., below which temperature it is a colourless, mobile liquid with a specific gravity of 1.732 at $4^{\circ} \mathrm{C}$. The specific gravity of the gas at normal temperature and pressure is $3.27(\mathrm{air}=1)$. It is colourless and has a faint, somewhat elusive, agreeable odour; but some commercial products used abroad possess a more penetrating odour owing to the presence of impurities. Familiarity lessens the acuity of the sense of smell in detecting its presence. It has a low water solubility, high chemical stability and no flash point.

Manufacture is generally carried out by heating at $130^{\circ} \mathrm{C}$. methyl alcohol with sodium or potassium bromide in excess of sulphuric acid, the chemical reaction being indicated thus:

$\mathrm{CH}_{3} \mathrm{OH}+\mathrm{NaBr}+\mathrm{H}_{2} \mathrm{SO}_{4} \rightarrow \mathrm{CH}_{3} \mathrm{Br}+\mathrm{H}_{2} \mathrm{O}+\mathrm{NaHSO}_{4}$.

The gas is washed and then condensed in refrigerator coils surrounded by brine; $\mathrm{CO}_{2}$ snow may also be used in small-scale trials. In this liquid state it is delivered in steel or copper cylinders to distributors who transfer it to smaller containers, with added nitrogen pressure. In the presence of oxygen, methyl bromide is decomposed by heat into hydrobromic acid, carbon dioxide and water. If air is restricted, a certain amount of carbon monoxide is likely to be formed. When the source of heat is a wood fire carbonyl bromide (bromophosgene), the less toxic representative of carbonyl chloride (phosgene) in the bromine series, is formed. If the source of heat is hot iron or a gas flame, free bromine may be liberated. Hydrolysis results in methyl alcohol and hydrobromic acid, a fact which may be of some importance in the toxicology of the substance.

$$
\mathrm{CH}_{3} \mathrm{Br}+\mathrm{H}_{2} \mathrm{O} \rightarrow \mathrm{CH}_{3} \mathrm{OH}+\mathrm{HBr} \text {. }
$$

\section{Uses}

The principal use to which methyl bromide is put in this country is that of extinguishing fires. Bulk for bulk, less is required for the purpose than any other known substance. It has, further, the advantage of being self-trajectory. A mixture with carbon tetrachloride is frequently used. Especially is methyl bromide recommended for fires involving celluloid or volatile hydrocarbons.

In America it is used effectively as a refrigerant.
Lethal effects upon insects and their larvae, rodents, nematodes and yeasts have commended its use for the delousing of clothing. For delousing, a 20 c.c. fabric protected ampoule is buried in the depths of one man's clothing, the ampoule broken by pressure with the foot and the whole (with equipment, in the case of a soldier) put into a tent of specially prepared material or in a concrete bin. After a lapse of some hours, the clothing is removed and hung on a line to aerate.

Other uses are fumigation of warehouses, flour mills, railway food vans, greenhouses and even of the soil itself. Its swiftly penetrating powers enable it to attack pests in stacks of grain, the pulp of fruits or the depths of a cheese in effective concentration and thereafter to dissipate quickly without detriment to germinating plants, with no harm to the consumer and little or no deterioration in flavour. As there is no fire hazard its value to the warehouseman is therefore considerable. It may ultimately have the effect of saving quarantine. Other uses of interest to the hygienist are the control of bed bugs (cimex lectularius) and plague, the latter by destruction of rats and ground squirrels together with their parasites. Before its dangerous properties were fully understood, a proposal was made to utilize the refrigerant effects of methyl bromide for local anaesthesia, but fortunately this was never put to the test.

The chemical industry has made use of methyl bromide as a methylating agent, but the iodide is usually preferred owing to its higher boiling point. Colour manufacturers also find uses for it.

\section{Incidence of Intoxication in Industry}

Constitutional symptoms of poisoning are experienced mainly among men engaged on manufacture; dermatological cases occur principally among those who fill small cylinders for distribution from the larger ones received from the manufacturer. The principle sources of danger are as follows:

1. Defects in Plant. Such faults as ill-fitting joints, fractures in delivery tubes, drips from delivery tubes, the displacement of vapour-laden air from collecting vessels are among the commonest. The great volatility of methyl bromide permits large quantities of gas to escape through a small leak. The odour is faint. Indeed, some are unable to perceive it at all and successive exposures dull the olfactory sense to its presence. Its 
low viscosity when in liquid form makes the prevention of drips from delivery tubes a formidable problem.

2. Poorly Disposed Plant. Any process, whether of manufacture or filling, which is carried out inside a building is potentially dangerous. Similarly, great precautions are necessary if methyl bromide is used to extinguish a fire in an enclosed space. Warning notices should be posted when fumigation is in process.

3. Cylinders of methyl bromide are liable to burst if the temperature is unduly raised. The liquid is then projected on to persons in the vicinity where rapid volatilization may cause poisoning.

4. Defects of the Workman. Careless or accidental overflow from a still or spilling of the liquid, failure to realize the dangerous character of the substance, insufficient training and experience in chemical process work, fumigating singly instead of in pairs, neglect of protective clothing such as masks and gloves and failure to ventilate fumigated rooms are the chief causes of poisoning.

\section{Clinical Picture}

Systemic effects are produced by inhalation of the gas and are manifested in the central nervous system; skin lesions arise through contact with the liquid or vapour. Cases of poisoning are commoner in warm weather than in cold seasons. Three stages in the progress of the disease may be described:

1. Premonitory Stage. After an incubation period lasting from 4 to 48 hours, the patient is affected by dimness of vision, diplopia, amblyopia, possibly lachrymation, staggering gait, headache, vertigo, vomiting, dilated pupils, perhaps euphoria and sometimes syncope. This condition persists for a few hours or days. Recovery may be complete or, after a brief remission, he enters the second stage. Röhrer (1920) emphasizes the importance of the remission, whilst Duvoir and others (1937) deny its existence.

2. Stage of Cerebral Irritation. This may be ushered in by jerkiness of the muscles (Röhrer, 1920) or brachial monoplegia (Duvoir, 1937). The chief characteristics are epileptiform convulsions, delirium and even acute mania. The skin is pale, the temperature normal or subnormal and sweating is profuse. Lôffler and Rütimeyer (1920) have noted opisthotonos and trismus. It is in this stage that death commonly occurs.

3. Recovery Stage. The succeeding symptoms depend on the part of the nervous system which bore the brunt of the attack and therefore these are variable. Optic atrophy has never been reported. Among the sequelae recorded in the literature are-hallucinations (Floret, 1915); apathy (Röhrer, 1920; Goldschmidt and Kühn, 1920; Floret, 1915; Duvoir and others, 1937; Jacquet, 1901: and Bing, 1910); amnesia (Cade and Mazel, 1923) aphasia (Duvoir and others, 1937); inco-ordination (Cade and Mazel, 1923; Duvoir and others, 1937); polyneuritis with defects of sensation, and tremor of hands and tongue (Goldschmidt and Kühn, 1920); insanity (Hamilton, 1925, 1934). The duration of this phase may last for months or even years.

Skin Lesions. Susceptibility to skin lesions increases with length of exposure and warmth of the skin. The appearances are of two types: dry, eczematous, cracked skin due to abstraction of fats, and blisters which may be sub-epithelial or subcutaneous. In the last-named lesion Nikolski's sign * may be elicited. The eczematous type may

* Nikolski's sign. If the tip of the observer's finger is pressed on the skin of a patient with well-developed pemphigus, or dermatitis herpetiformis, or epidermolysis bullosa, the horny layer of the epidermis will be felt to slide on the underlying layers and may even be pushed off. lead to a general sensitivity evidenced by erythema of any part of the body and puffiness of the loose tissues of the eyelids. The incubation period in the formation of blisters varies, but is generally about 4 hours. No case of constitutional symptoms from skin absorption has so far been recorded in the literature; and while the symptoms in case 4 recorded below may have arisen in this way, the man was also exposed to methyl bromide in the atmosphere and inhalation is the more likely portal of entry of the methyl bromide.

Burns with $\mathrm{CO}_{2}$ snow may occur in men engaged on pilot trials or on the manufacture of methyl bromide in the laboratory. They can be differentiated from $\mathrm{CH}_{3} \mathrm{Br}$ blisters by the absence of premonitory pruritis and the tendency of the latter to form large blisters by coalescence of numerous pinpoint vesicles. Surrounding redness and oedema are also less, whilst the blister fluid is more liquid with $\mathrm{CO}_{2}$ burns.

The following nine cases serve to illustrate the symptoms that may occur. There was vomiting in four instances; a drunken sensation and blurring of vision in three; giddiness, delirium and unconsciousness in two; while tinnitus, convulsions, amnesia, thirst and abdominal pain each occurred in one patient. The most prominent physical signs were slow, hesitant or confused speech, staggering gait, tremor, inco-ordination as evidenced by the fingernose test, and cyanosis. Skin lesions occurred in three patients and itching was a constant symptom; these lesions consisted either of large blisters or small herpetiform vesicles. Conjunctivitis occurred in one man as a result of a splash in the eye.

\section{Case Notes}

Case 1. (J. T. K. Male. Age 40.) Whilst carrying out repairs to an engine on a yacht on January 25,1937 a fire occurred which was extinguished by means of methyl bromide. It is estimated that a concentration of at least 60,000 p.p.m. by volume of methyl bromide in the atmosphere was attained. The hatchway in the roof of the engine compartment was open to the saloon and there was a small opening for ventilation at one end of the compartment. The patient continued to work for two hours after extinguishing the fire. He then complained of giddiness, vomited several times, became delirious and collapsed.

On examination, the patient was cyanosed, respirations were very rapid and there were frequent, generalized convulsions. The pulse was accelerated. Pupil reflexes were present but in ordinary daylight were pin-point No other abnormal neurological findings were elicited. Death took place about an hour later.

At necropsy the lungs were found to be very congested and oedematous. The bronchi were inflamed. There was congestion and cloudy swelling of the kidneys and congestion of the brain and stomach.

Case 2. (J. A. S. Male. Age 31.) He had formerly worked with benzene for nine years, but had been engaged on the manufacture of methyl bromide for six weeks. His job consisted in wheeling ice along a draughty passage to the plant, which was in the open air. Once or twice during each shift he entered a chamber of 200 cubic feet capacity to run liquid methyl bromide into a cylinder. The chamber was exhausted by a fan at the rate of 580 cubic feet per minute, the fan 
being placed near the floor. The night temperature for the 9th-10th January, 1939 , was $42^{\circ} \mathrm{F} .\left(5 \cdot 5^{\circ} \mathrm{C}\right.$.), i.e. $1^{\circ} \mathrm{C}$. above the boiling point of methyl bromide.

During the night 10th-11th January, the patient experienced occasional blurring of vision and tinnitus. On the morning of the 11 th, as he was going home from work, he felt giddy and was affected by temporary blindness which lasted several minutes. He felt like a drunken man and had to cling to a lamp-post. Recovering somewhat, he made his way home by train and that evening vomited several times. He felt weak, giddy and faint. Of events between the 11th and 16th his memory was a complete blank.

Examination on the 11th showed him to be drowsy, slow and hesitant of speech, there were coarse tremors of the hands, dilatation of the pupils and general muscular weakness. A curious kind of euphoria was noted. Neurological examination was negative. Cerebrospinal fluid appeared to escape under pressure through the needle. It was found to contain:-total protein, $40 \mathrm{mgm} . / \mathrm{ml}$.; globulin, nil; sugar, $91 \mathrm{mgm} . / \mathrm{ml}$.; urea, $32 \mathrm{mgm}$./ml.; chlorides, $740 \mathrm{mgm}$. $/ \mathrm{ml}$.; cells-W.B.C., 2/c.mm., R.B.C., $20 /$ c.mm.; blood sugar, $100 \mathrm{mgm} . / \mathrm{ml}$. The patient made a full recovery.

Case 3. (H. W. B. Male. Age 35.) Had worked on the manufacture of methyl bromide since October, 1938. He left for work on the evening of the 16th October, 1939, feeling perfectly well. The last thing he remembered was returning home for his (civilian) gas mask. In the early hours of the following morning he was found lying unconscious on the ground, near the plant. On admission to hospital at 7.15 a.m., on the 17th October, 1939, he was unconscious, cyanosed, sweating profusely and having epileptiform convulsions every 10 minutes. Oxygen was administered with some apparent benefit. On lumbar puncture, the fluid did not escape under pressure. It was opalescent, watery and contained small flakes. A centrifuged specimen showed only a few lymphocytes. Protein amounted to $45 \mathrm{mgm}$. $/ 100 \mathrm{ml}$. Sugar content was normal. Bromine content was $16 \mathrm{mgm} .100 \mathrm{ml}$. (normal, $1 \mathrm{mgm}$.). Blood count:-R.B.C., 4.4 million; W.B.C., 9,800; polymorphs, 90 per cent.; lymphocytes, 8 per cent.; monocytes, 2 per cent.; eosinophils, nil. Blood sugar, $80 \mathrm{mgm}$. Blood urea, $65 \mathrm{mgm}$. on 18.10.39; $45 \mathrm{mgm}$. on 20.10 .39 .

During the 17th and 18th he was delirious. On the 19th he was drowsy, his speech slow and he tended to stammer, but he could answer questions intelligently. Complete amnesia was present for events since he had left his home on the evening of the 16th. He had experienced bizarre dreams. The fingers and tongue showed a coarse tremor; he was unable to shave himself or write. There was marked inco-ordination with the finger-nose test. The abdominal reflexes were not elicited and the left plantar reflex equivocal. He complained that lemonade tasted like 'rotten cabbages' and cigarettes like 'rotten leaves.' He appeared to enjoy both food and tobacco whilst in hospital.

By July, 1940, he had made a fair recovery and was working, but not at his old job. His speech was slurred and jerky. He appeared to split all movements into their component parts and having once initiated a movement found difficulty in controlling it. Thus, his writing was laboured and the pen tended to fly off the paper with up-strokes. When he grasped the rail of a bus in the act of boarding it, he found he could not let go. On taking coins from one hand to the other he sometimes jerked a coin into the air. If he was walking and turned sharply, his knees gave way, causing him to fall. Adiodokokinesis was present. Rombergism was not elicited. The deep reflexes were brisk; ankle clonus was present on the left side. Abdominal reflexes had returned. Pupillary reactions were normal as were his discs. He was possessed of a sense of inferiority and his self-respect seemed to have suffered an injury. Full recovery took place when a voluntary monetary settlement was made in 1943.
Case 4. (A. M. Male. Age 27.) Engaged as a filler on a methyl bromide plant from the 18th to 30th October, 1939. The job was carried out in the open air. A thick-walled rubber tube was securely fastened to a copper bottle and after exhausting the air from the bottle liquid methyl bromide was run in under $50 \mathrm{lb}$. per square inch pressure of nitrogen. When the tube was removed, a few drops of methyl bromide were liable to drip on to the backs of the operator's hands. The patient had not worn gloves and this accident had happened several times.

On the 30th October, 1939, a considerable quantity of methyl bromide was spilled on to the backs of both hands. Some hours later, on the same day, he experienced upper abdominal pain and vomited. $\mathrm{He}$ felt drowsy and 'muddled.' His gait was staggering. Blisters were present on the backs of his hands near the webs of the fingers when he was admitted to hospital on the $31 \mathrm{st}$. He discharged himself the following day, saying he felt quite well. On the 2nd November, he complained of thirst, weakness, anorexia and was unable to sleep. By the evening he was mildly delusional. Neurological examination was negative. The urine was normal. He was fully recovered by the 10th and only a few ragged tags of epithelium marked the sites of the blisters.

Case 5. (B. F. Male. Age 17.) Worked in a fully enclosed filling shop for 18 months, during 3 months of which he had actually worked as a filler. Carbon tetrachloride was also used in a mixture with methyl bromide and the machine for filling this mixture was situated next to one which delivered methyl bromide only. Drips collected in the seals on the bottles and were shaken down on to the floor in an enclosed space exhausted by a powerful exhaust system. The pure methyl bromide was coloured and the sides of the bottles were liberally stained. A year before his illness he had suffered from a crop of blisters on his hands which were ascribed to contact with methyl bromide.

During August, 1944, he began to experience weakness in his knees which was particularly noticeable when he made a sharp turning motion. On one occasion, whilst running for a bus, he actually fell. He began to see double. His appetite was good and he slept well; there was no headache, nausea or vomiting. As time went on it was noticed that he tended to stagger "like a drunken man' but he did not feel giddy. He began to stammer. On the 6th September his memory was affected; he could not remember the numbers of his bottles. He could usually see clearly when looking straight in front. When he looked at the ground he could only 'see light' for a minute or two and then objects were perceptible but blurred. After three days' rest in bed he recovered and returned to work on the 28th October. No opportunity was found to examine him prior to that date when he said he felt better than ever and no objective signs could be elicited.

Case 6. (D. R. G. Male. Age 25.) Foreman, filling plant. On the 12th June, 1940, he remembered spilling some methyl bromide on to his boots. On the 15 th he noticed considerable irritation between his toes and on the dorsum of his feet. Blisters were present on the 16th, when itching ceased. Healing had taken place by the 22 nd except for a deep fissure between the fourth toe of the right foot and the sole, which took some weeks to heal.

On the 29th June, 1940, he spilled some methyl bromide on his hands. About 5 or 6 hours later itching of the fingers was intense. The skin of the fingers became swollen, tense and congested and pin-point vesicles appeared on the sides and webs of the fingers the following day. The vesicles rapidly increased in size and appeared to run together so that by the 2 nd July he had several blisters a centimetre in diameter. Meanwhile, the itching had subsided. On the 6th July an erythematous, papular rash appeared on the flexor aspects of his forearms and on the extensor aspects of his legs. He did not feel well and had no inclination? 
for food. The condition spread to his shoulders and chest and reached its height by the 8th July, gradually subsiding until the whole condition was well by the 18th July.

Case 7. (J. F. Male. Age 40.) Manufacturing plant. At 4.15 p.m. on the 17 th July, 1943, he removed some caustic soda, with the right hand gloved, from a scrubber containing methyl bromide vapour. About a quarter of an hour later the back of the hand began to itch. At 8 o'clock it was red, swollen and showed numerous pin-point vesicles. At this stage itching ceased. An hour later the vesicles appeared to have coalesced so that one huge blister enveloped the back of the hand and fingers. The contents of the blister were pale straw in colour and gelatinous. Paracentesis only resulted in rapid replacement of the contents and the condition remained stationary for three days until the epithelium was removed. After that, progress was rapid and full recovery had taken place eight days after the accident.

Case 8. (L.G. Male. Age 30.) Filler. Received a splash of methyl bromide in the right eye. Pain was immediate and conjunctivitis rapidly developed, subsiding without corneal ulceration or constitutional symptoms, in three weeks.

Case 9. (A. B. Male. Age 32.) Applied his mouth to a tube connected with a cylinder of methyl bromide and opened the stop-cock, thinking he could raise sufficient pressure in the tube to prevent the substance entering his mouth. In this his expectations failed to materialize and his mouth was forcibly filled with methyl bromide. He asserted he swallowed some of the fluid, but his reaction to the incident was so violent that this is doubtful. The only effect appeared to be an intense thirst which cleared up in a few days and he returned to work in a week.

\section{Pathology}

Pathological findings are obscure but it would seem, both from animal experiments and in man, that if a satisfactory technique is used, an increased bromine content can be demonstrated in the cerebrospinal fluid. In Röhrer's (1920) case the differential blood count showed 40 per cent. mononuclears. There was no abnormality of the red cells. Albuminuria was present, but no sugar or acetone. The autopsies in the two fatal cases of Goldschmidt and Kühn (1920) showed acute purulent bronchitis, inflammation and oedema of the lungs, dark-red fluid blood and slight fatty degeneration of the ganglion cells of the brain. In the case recorded by Löffler and Rütimeyer (1920) albuminuria was present and there was a polymorphonuclear leucocytosis. The fatal cases recorded by Duvoir and his associates (1937) revealed intense congestion of the internal organs, particularly of the lungs. Alice Hamilton (1934) records congestion and oedema of the lungs, injury to the vascular system as shown by the tendency to haemorrhages, and degenerative changes especially in the kidneys.

\section{Mode of Action}

The following theories have been advanced to explain the mode of action of methyl bromide:

1. The substance enters the circulation unchanged and attacks the central nervous system by virtue of its lipide solvent properties. Unsaturated fatty acids, present in phospholipides, are readily halogenated, forming additional products at their double bond, thus: $\mathrm{R}-\mathrm{CH}: \mathrm{CH}-\mathrm{R}+\mathrm{Br}_{2} \rightarrow \mathrm{R}-\mathrm{CHBr}-\mathrm{CHBr}-\mathrm{R}$. If lecithin be taken as an example, its function in the production of acetyl choline and consequent transmission of nerve impulses would be seriously impaired.

2. It has been shown that the class of halogenated compounds to which methyl bromide belongs, may be hydrolysed in the body to methyl alcohol and the halogen acid. The toxic effects of methyl bromide might then be ascribed to hydrobromic acid, but the characteristic effect of methyl alcohol, optic atrophy - a phenomenon not so far known to occur-would also be expected. Also, if poisoning occurred by this disintegration the relative toxicities of the series would be in the order of their molecular weights, which is not the case. Moreover, Irish, Adams, Spencer and Rowe $(1940,1941)$ have shown that the toxicity of methyl alcohol and sodium bromide administered separately to rabbits is not comparable to an equivalent amount of methyl bromide.

3. Henderson and Haggard (1937) suggested that whilst the dissociated bromine ion remains in the extracellular water, the undecomposed methyl bromide may (like many hydrocarbons) pass the cell membrane. Intracellular decomposition might then yield more severe and perhaps unique effects from the bromide with retarded elimination.

\section{Effects upon Animals}

Animal experiments have provided useful commentary on the clinical and pathological findings in men. Löffler and Rütimeyer (1920), experimenting on guinea-pigs, found that if an animal lived 30-70 minutes after exposure to methyl bromide in gaseous form, no bromine could be demonstrated in the body; but if the animal were killed immediately after exposure, bromine could be demonstrated. Glaser and Frisch (1929) showed that animals tolerate larger concentrations of methyl bromide for a short time better than lower concentrations for long periods. Sayers, Yant, Thomas and Berger (1929) found that the symptoms of poisoning in guinea-pigs were excitement, loss of equilibrium, struggling, weakness, rapid pulse, convulsive and rapid respirations, râles and in some cases a frothy, bloody exudate from the nostrils. Nuckolls's (1933) experiments on 12 guinea-pigs, exposed in groups of three, to increasing concentrations for different periods of time, indicated increasing local effects on the skin and mucous membranes such as scratching, lachrymation, sniffing, coughing and retching. Other effects were tremors, weakness and lethargy. Sayers and his colleagues (1929) summarize the pathological findings in guinea-pigs as degeneration of heart muscle, congestion of the lungs with haemorrhages and oedema, congestion and degeneration of the liver, which is occasionally slategrey in colour, and congestion of other viscera such as the pancreas, kidneys, intestines and brain. In general, it was found that the changes were most severe in animals which die within 24 hours following long exposure to low concentrations. In many 
cases there appeared to be a delayed action. Hermann and Vial (1935) produced ventricular fibrillation in chloralosed dogs poisoned by methyl bromide. Duvoir et al. (1937) produced symptoms in rabbits similar to those they had observed in men.

\section{Effects on Vegetables and Organic Materials}

The effects of methyl bromide on materials are of interest in their relation to work such as the delousing of clothing and on account of blisters on the feet of workmen whose boots have been contaminated by methyl bromide. Fruits and vegetables were used by Dudley (1939) in a series of tests. He fumigated samples for 2-24 hours with $2 \mathrm{lb}$. of methyl bromide in 100 cubic feet of air. Absorption took place up to 6 or $7 \mathrm{mgm}$. of methyl bromide per $100 \mathrm{gm}$. of sample. Much of this was lost in 48 hours. Concentrations used for fumigation vary from 1 to $5 \mathrm{lb}$. per 1000 cubic feet for periods lasting from $1 \frac{1}{2}$ to 24 hours. Substantially increased amounts of bromide were found by Anderson (1941) in fumigated wheat and flour, but he did not consider the amounts harmful to the consumer: Nevertheless, he thought that repeated fumigation might not be without danger. Knott and Claypool (1941), in studies on the respiration rate of mature green tomatoes, found a sharp increase in the $\mathrm{CO}_{2}$ output, amounting to as much as 300 per cent.

\section{Plant Hygiene and Preventive Measures}

As with most industrial aiseases, hygiene of the place of work is of much greater importance than treatment. Here it resolves itself into the prevention of leaks and adequate dilution of escaping gas. The siting of plant in the open air, preferably in a passage between two buildings where a current of fresh air can be relied upon, is of the greatest importance. Cylinders of methyl bromide should not be stored in a workroom. Instruction to chemists and workmen in the dangerous properties of the substance is of first importance. The incidence of poisoning among inexperienced workmen is strikingly higher than among old hands. It should be the responsibility of one man to issue, examine periodically, and repair gas masks. This work may readily be combined with the maintenance of other apparatus, such as eye douches and firstaid boxes in other parts of the factory, medical stores and assistance in the health department. Some care and experience is necessary to maintain gas masks in a safe condition. The most insidious defect is the partial transverse fracture in corrugations of the rubber tube. In the normal position, the crack is invisible and closed, but on bending the tube, as may happen at intervals when the mask is in use, a gap appears through which dangerous quantities of gas may penetrate to the lungs of the workman. Temporarily sealed joints are the weakest points in what should be the closed system of the manufacturing or filling plant.

Where possible, pipework should be of copper, as this metal does not flake and block delivery tubes. Plastic, heavy rubber or neoprene tubing may be used. Methyl bromide has a solvent action on grease and gasket materials. A good grade of soap should therefore be used for the lubrication of threaded pipework; and sheet lead, soft copper, leather or hard felt for gasket materials. Neoprene, sponge or hard rubber tend to soften when exposed to methyl bromide under pressure. The use of the halide leak detector lamp has not fulfilled expectations, but improvements may be anticipated.

It has been suggested that volatile colouring agents or substances with penetrating odours or lachrymatory effects might be added to methyl bromide as safety measures. Technical difficulties, however, are very great. The colouring substance would require to be at least as volatile as the substance it was intended to betray, whilst an odour should be of such a character that it did not escape too readily and yet would give sufficient warning of danger. Colouring matter is, indeed, frequently added but only for the purpose of indicating material which has been sprayed by an automatic, thermostatically controlled extinguisher and so give notice not only that a fire has occurred but also that the extinguisher must be replenished. Periodic medical examinations help not only in the detection of early or slight symptoms, but a sympathetic hearing of the workers may lead to the repair of dangerous mechanical parts. If many of these latter complaints are without foundation they are still worth while if they do, on occasion, lead to some important preventive measure. Bathing the hands in a weak solution of sodium carbonate may help to prevent skin lesions by promoting the decomposition of methyl bromide.

\section{Treatment}

Little can be done in the way of treatment when symptoms are established. Oxygen may be administered if there is cyanosis. Lumbar puncture should be carried out for diagnostic purposes. Ammonium carbonate may be given in the hope of decelerating vascular damage; adrenalin has no effect in this direction and may, indeed, produce fatal ventricular fibrillation.

\section{Safe Concentrations}

A safe concentration for methyl bromide has not so far been established. Henderson and Haggard (1927) classify it as belonging to that group of anaesthetic gases and vapours in which the toxic properties are in inverse proportion to the anaesthetic values, in contradistinction to the primary anaesthetics. They consider methyl bromide 14.5 times as toxic as carbon tetrachloride after brief exposures, but it is only twice as toxic for prolonged exposures. The difference is perhaps accountable by the fact that the effects on the nervous system by methyl bromide are evident within a period of days, whereas the toxic effects of carbon tetrachloride on the liver are only evident when the reserve of that 
organ is exhausted. The National Safety Council of the U.S.A. regard 1000 parts per million as the upper limit for carbon tetrachloride in the avoidance of acute poisoning. Davis (1934) and Smyth and Smyth (1936) regard 100 parts per million as the upper limit for 8-hour exposures. According to Henderson and Haggard's (1927) data, therefore, 70 parts per million would be the upper safety limit for short exposures to methyl bromide and 50 parts per million for 8-hour exposures.

\section{Medico-legal Aspects}

Compensation for methyl bromide poisoning is regulated by the Workmen's Compensation (Industrial Diseases) Order, S. R. \& O. No. 642 of 1941, extending the provisions of Section 43 of the Workmen's Compensation Act, 1925, to 'poisoning by methyl bromide or its sequelae.' The second column indicates that poisoning must occur in ' any process involving exposure to the fume of methyl bromide.' It must, of course, also conform to the other requirements of the Act. The Order came into force on June 1,1941. The difficulties of proving an accident prior to that date had been due to such factors as the latent period before the onset of symptoms, the insidious character of the substance which often defied any attempt to say how, when, or in what circumstances a spill or leak occurred and ignorance of the symptoms of poisoning causing delay in making application for compensation within the statutory period.

The disease is not included in the fourteen industrial diseases notifiable by medical practitioners to H.M. Chief Inspector of Factories in accordance with section 66 of the Factories Act, 1937, and Orders made under that section; nor is it neccessary for the occupier to notify H.M. District Inspector of Factories and the factory Examining Surgeon. The provisions of section 64 of the Act with regard to accidents are also made to apply to the notification of the specified industrial diseases. It is also of importance to remember that the Dangerous Occurrences Notification Order, 1935, No. 1046, prescribes that in the event of a 'container used for the storage at a pressure greater than atmospheric pressure of any gas or gases (including air) or any liquid or solid resulting from the compression of gas' exploding, the fact must be notified to an inspector.
Summary

Nine cases of intoxication from methyl bromide, occurring in industry, are reported. Vomiting occurred in four instances; a drunken sensation and blurring of vision in three; giddiness, delirium and unconsciousness in two; while tinnitus, convulsions, amnesia, thirst and abdominal pain each occurred in one case. Slow, hesitant speech, staggering gait, tremor and cyanosis were the most prominent physical signs. Three men showed skin lesions, consisting either of large blisters or small herpetiform vesicles. Itching was a characteristic of these lesions. One man developed conjunctivitis as a result of a splash in the eye.

Death occurred in one case. Necropsy revealed congested and oedematous lungs, cloudy swelling in the kidneys and congestion of brain and stomach.

A bromine level of $16 \mathrm{mgm}$. per $100 \mathrm{ml}$. was found in the cerebro-spinal fluid in one man.

The uses, incidence of intoxication, pathology, prevention and treatment are discussed, and the literature is reviewed. There is a note on medicolegal aspects.

The safe concentration of methyl bromide in the atmosphere was estimated to be 70 parts per million for short exposures, and 50 parts per million for exposures of 8 hours.

\section{REFERENCES}

Anderson, J. A. (1941). Dept. Trade Comm., Grain Res. Lab. Winnipeg, Ann. Rep. 15, 29.

Bing, S. (1910), quoted by Röhrer $(v, i)$

Cade, A., and Mazel, F. (1923). Bull. Mém. Soc. med. Hôp. Paris, 47, 722.

Carozzi, O. L. (1934). Occupation and Health, Geneva, 2, 238.

Davis, P. A. (1934). J. Amer. med. Ass., 103, 961.

Dudley, H. C. (1939). J. industr. eng. Chem., Anal. Ed. 259.

Duvoir, M., Fabre, R., et Layani, F. (1937). Bull. Mém. Soc. méd. Hôp. Paris, 34, 1540.

Floret, F. (1915). (1939). Bull. Soc. pharmacol., 46, 15.

Glaser, E. (1928). Dtsch. Z. ges. gerichtl. Med., 12, 470.

Gol, and Frisch, S. (1929). Arch. Hyg., 101, 48.

Goldschmidt, E., and Kühn, E. (1920). Z Zbl. Gewerbehyg., 8, 28. Hamilton, A. (1925). Industrial Poisons in the U.S.A., New York, p. 450.

(1934). Industrial Toxicology, New York, p. 228.
Henderson, Y., Haggard, H. W. (1927). Noxious gases and the principles of respiration influencing their action, New York.

Hermann, H., and Vial, J. (1935). C. R. Soc. Biol., Paris, 119, 1316. Irish, D. D., Adams, E. M., Spencer, H. C., and Rowe, V. K. (1940) J. industr. Hyg., 22, 218.

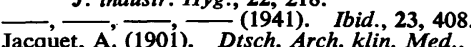

Knott, J. E., and Claypool, L. L. (1941). Proc. Amer. Soc. hort. Sci.

Löffler, W., and Rütimeter, W. (1920). Viert. gerichtl. Med. $60,60$. Nuckolls, A. H. (1933). Underwriters Labs. Misc. Hazards, No. 2375,

p. 118. $\quad$ Viert. gericht. Med., 9, 51.

Sayers, R. R., Yant, W. P., Thomas, B. G. H., and Berger, L. B (1929), U.S. Treasury Dept. Public Health Service Bull.

Smyth, H. F., and Smyth, H. F. (1936. J. industr. Hyg., 18, 277 